\title{
Epidemiology and characteristics of childhood glaucoma: results from the Dallas Glaucoma Registry
}

This article was published in the following Dove Press journal:

Clinical Ophthalmology

27 August 2013

Number of times this article has been viewed

\section{Derrick S Fung \\ MAllison Roensch \\ Karanjit S Kooner \\ $\mathrm{H}$ Dwight Cavanagh \\ Jess TWhitson}

Department of Ophthalmology,

University of Texas Southwestern

Medical Center, Dallas, TX, USA
Correspondence: Jess T Whitson Department of Ophthalmology, University of Texas Southwestern Medical Center, 5323 Harry Hines Blvd, Dallas, Texas, USA 75390-9057

$\mathrm{Tel}+$ I 2146484733

Fax + I 2146482469

Email jess.whitson@utsouthwestern.edu
Purpose: Few studies have provided epidemiological characteristics of childhood glaucoma in a large, multiethnic population. This information is important if we are to better screen for and characterize this specific type of glaucoma. In this study, we evaluate the characteristics of patients with childhood glaucoma, including glaucoma suspects, as identified through the Dallas Glaucoma Registry (DGR).

Patients and methods: The DGR catalogs the characteristics of glaucoma patients seen at University of Texas Southwestern Medical Center, an academic tertiary referral center for a large, multiethnic, urban population in the United States. We analyzed these patients with respect to race, medical and surgical treatment, cup-to-disc ratio, intraocular pressure, and visual outcomes.

Results: The study comprised 376 eyes of 239 childhood glaucoma patients, of whom 19\% had primary congenital glaucoma, $4 \%$ had primary juvenile glaucoma, $45 \%$ had secondary glaucoma, and 31\% were glaucoma suspects. Trauma and postsurgical aphakia were the most common causes for secondary glaucoma. Thirty-eight percent of patients were Hispanic, 30\% were Caucasian, 21\% were African American, 3\% were Asian, and 9\% were unknown or unreported. Male sex was more common at 56\%. Of all eyes with glaucoma, $65 \%$ received surgical intervention while $70 \%$ required at least one medication for intraocular pressure control. Trabeculotomy and tube-shunt surgery were the most common surgeries performed. Of patients who could have Snellen visual acuity measured, glaucoma suspect eyes had the largest proportion of eyes (96\%) with good visual acuity (better than 20/40) while primary congenital glaucoma eyes had the smallest proportion (41\%) with good visual acuity. Secondary glaucoma eyes had the largest proportion of eyes (30\%) with poor visual acuity (worse than count fingers).

Conclusion: The most common etiologies of childhood glaucoma were primary congenital glaucoma and secondary causes including trauma and postsurgical aphakia. A high proportion of glaucoma patients were of Hispanic background, reflecting the patient population studied. Trabeculotomy and tube-shunt surgery were the most common surgical interventions performed.

Keywords: congenital glaucoma, childhood glaucoma, epidemiology, characteristics

\section{Introduction}

Visual impairment is a debilitating condition that frequently adversely impacts quality of life and prevents patients from performing simple tasks necessary for independent living. In children, visual impairment, even due to reversible causes, can be compounded by amblyopia, which leads to lifelong disability for the individual. Glaucoma in childhood is a rare, serious cause of blindness around the world, but it is treatable. Glaucoma is the second leading cause of vision loss in people of all ages around 
the world, and childhood glaucoma is estimated to cause a significant percentage of blindness in children, from $1.2 \%$ of children in Great Britain, 3\% in northern India, to $7 \%$ in southern India. ${ }^{1-3}$

The disease is complex in nature and characterized by elevated intraocular pressure (IOP), optic disc cupping, and progressive visual field loss. Early detection is critical, for treatment before corneal damage, optic nerve damage, and amblyopia occur can lead to significantly improved visual outcomes.

In Great Britain, Papadopoulos et al looked at 99 children with newly diagnosed glaucoma and found the annual incidence of primary congenital glaucoma to be one out of 18,500 live births. ${ }^{4}$ Forty-seven children had primary glaucoma and 52 had secondary glaucoma. They found that primary congenital glaucoma is more common in children of South Asian origin, and they did not find a difference in sex predilection, although another study has suggested that males have an increased incidence of primary congenital glaucoma. ${ }^{5}$

In Toronto, ON, Canada, Taylor et al presented a review of 306 children diagnosed with childhood glaucoma. ${ }^{6}$ They found congenital glaucoma to be the most common $(38 \%$ of all patients) followed by aphakic glaucoma (20\%) and Sturge-Weber syndrome-associated glaucoma (10\%). Those patients with congenital glaucoma presented at a younger age and frequently required multiple surgeries. The visual prognosis depended highly on the underlying type of glaucoma.

A recent population-based study of residents in Olmstead County, MN, USA found an incidence of childhood glaucoma of 2.29 out of 100,000 residents 20 years old or younger. ${ }^{7}$ This population was predominantly white $(96 \%)$, yet a quarter of patients who were diagnosed with glaucoma were of another race. They found that traumatic and surgical causes for glaucoma were the most common.

While the incidence of childhood glaucoma has been well documented in the Western world, other populations have shown a higher incidence of congenital glaucoma, including those in India and the Middle East and gypsies in Slovakia. $^{8-10}$

From the Tongren Hospital in Beijing, People's Republic of China, servicing a large Chinese population, Qiao et al presented 1,055 patients with pediatric glaucoma seen from 2002 to $2008 .{ }^{5}$ Congenital glaucoma was again the most common type, seen in $46 \%$ of all patients, followed by traumatic glaucoma (12\%) and aphakic glaucoma (9\%). Patients were more commonly male in all types of glaucoma, with a sex ratio of 2.32 to one. Congenital glaucoma patients tended to be younger at presentation (below 2 years of age), and traumatic glaucoma patients were found to be older (between 10 and 15 years of age).

Primary congenital glaucoma, the most common primary childhood glaucoma, is believed to be caused by dysplasia of the anterior chamber angle, and it is generally bilateral. ${ }^{4,6,11}$ While primary congenital glaucoma is generally sporadic or autosomal recessive, juvenile glaucoma is often autosomal dominant. ${ }^{11-13}$ Treatment for primary childhood glaucoma is primarily surgical, although glaucoma medications also play an important part in treating patients both before and after surgery. The majority of surgeries for all types of pediatric glaucoma are successful, although amblyopia often limits long-term visual potential. ${ }^{11,14}$

Secondary glaucoma is defined as glaucoma associated with other ocular or systemic disorders and is common in children. ${ }^{15}$ Frequent causes of secondary glaucoma in children include trauma, lens-related disorders, phakomatoses, uveitis, anterior segment dysgenesis syndromes, and aniridia. ${ }^{4,6}$

The Dallas Glaucoma Registry (DGR) was established in 2005 as a mechanism to collect epidemiologic and clinical information on patients seen at the University of Texas Southwestern Medical Center, Dallas, TX, USA and its affiliated clinics serving the North Texas region. ${ }^{16}$ This registry included many patients with various types of glaucoma, including childhood glaucoma, from a diverse racial mix in the North Texas area. The United States Census Bureau estimated the racial makeup of Dallas County in 2011 to be $32.8 \%$ Caucasian (63.4\% nationally), 22.5\% African American (13.1\% nationally), 38.9\% Hispanic or Latino (16.7\% nationally), and 5.3\% Asian (5.0\% nationally). ${ }^{17}$ This racial diversity makes North Texas an ideal place to establish this registry.

This study evaluates the characteristics of patients with childhood glaucoma and childhood glaucoma suspects in the DGR, including race, medical and surgical treatment, visual outcomes, and IOP control.

\section{Methods}

Appropriate Institutional Review Board approvals were obtained and strictly implemented. Information on participating physicians and physician-specific patient data remains confidential. No physician-to-physician data comparisons were made.

Patients eligible for the study were identified by a search of medical records at the Children's Medical Center of Dallas, affiliated with the University of Texas Southwestern Medical 
Center for all patients seen between June 2005 and July 2009 with the following diagnoses and International Classification of Diseases, 9th edition, codes: glaucoma suspect (365.00); ocular hypertension (365.04); glaucoma of childhood (365.14); glaucoma associated with an unspecified ocular disorder (365.60); glaucoma associated with ocular trauma (365.65); unspecified glaucoma (365.9); and buphthalmos (743.20). Once these patients were identified, they were further classified into glaucoma subtypes similarly to previous studies. ${ }^{46}$ Primary congenital glaucoma was defined as an idiopathic glaucoma arising in children under 3 years of age. Primary juvenile glaucoma was defined as an idiopathic glaucoma arising in children 3 years of age or older. Secondary glaucoma was defined as glaucoma associated with other ocular or systemic abnormalities. These other abnormalities included trauma, postsurgical changes, Sturge-Weber syndrome, anterior segment dysgenesis syndromes, and other causes. Glaucoma suspect patients were based upon one of the following criteria: IOP $>21 \mathrm{mmHg}$; suspicious optic disc with an increased or asymmetric cup-to-disc ratio; family history of glaucoma; or other systemic condition associated with glaucoma.

We used a data collection form to gather epidemiological and clinical disease information: age; race; sex; glaucoma diagnoses; glaucoma medications; types of glaucoma surgery; most recent best-corrected visual acuity; most recent IOP; and cup-to-disc ratio. We retrospectively collected all clinical data, and each patient was enrolled only once in the registry regardless of the number of clinic visits. When multiple clinic visits were present, we gathered clinical information from the most recent clinic visit.

\section{Results}

A total of 239 unique pediatric patients were examined between June 2005 and July 2009, and a retrospective chart review was performed on these patients. Patients with primary congenital glaucoma comprised $19 \%$ of all glaucoma patients in the study, and primary juvenile glaucoma accounted for $4 \%$ of all patients in the study. Forty-five percent of patients carried a diagnosis of secondary glaucoma, and 31\% were glaucoma suspects. The number of patients, sex, and number of eyes based on type of childhood glaucoma are presented in Table 1. Fifty-six percent of all patients were male, with trauma-related glaucoma having the highest percentage of male patients at $72 \%$. The study population consisted of $38 \%$ Hispanic, 30\% Caucasian, 21\% African American, and $3 \%$ Asian children (see Table 2). For $9 \%$ of patients, racial background was unlisted or simply listed as "other" in the medical record, with no further specification.
Table I Types of childhood glaucoma in the study patients

\begin{tabular}{llll}
\hline & $\begin{array}{l}\text { Number } \\
\text { of patients } \\
\text { (\% of total) }\end{array}$ & $\begin{array}{l}\text { Male sex, } \\
\mathbf{n}(\%)\end{array}$ & $\begin{array}{l}\text { Number } \\
\text { of eyes }\end{array}$ \\
\hline Total & 239 & $133(55.6)$ & 376 \\
Primary congenital glaucoma & $46(19.2)$ & $25(54.3)$ & 81 \\
Primary juvenile glaucoma & $10(4.2)$ & $4(40.0)$ & 19 \\
Secondary glaucoma & $108(45.2)$ & $64(59.3)$ & 140 \\
$\quad$ Trauma & $32(13.4)$ & $23(71.9)$ & 32 \\
$\begin{array}{l}\text { Postsurgical } \\
\text { Sturge-Weber syndrome }\end{array}$ & $30(12.6)$ & $15(50.0)$ & 30 \\
$\quad$ Anterior segment & $18(7.5)$ & $10(55.6)$ & 21 \\
$\quad$ dysgenesis & $6(6.7)$ & $6(37.5)$ & 27 \\
$\quad$ Other & $12(5.0)$ & $10(83.3)$ & 14 \\
Glaucoma suspect & $75(31.4)$ & $40(53.3)$ & 136 \\
\hline
\end{tabular}

Patient clinical characteristics and treatment modality based on eyes are presented in Table 3. On average, IOP was less than $21 \mathrm{mmHg}$ for all groups. Excluding glaucoma suspects, $65 \%$ of all eyes underwent at least one glaucoma surgery and $70 \%$ were on at least one glaucoma medication at the most recent visit. The mean number of medications for all patients was 1.25 , and the mean number for those patients on medications was 2.25 . Topical carbonic anhydrase inhibitors, prostaglandin analogs, and beta-blockers were used most often, while alpha-agonists and systemic carbonic anhydrase inhibitors were used least often. The most common surgical procedure performed was trabeculotomy, followed by tubeshunt surgery, as shown in Table 4.

\section{Primary congenital glaucoma}

A total of 46 patients and 81 eyes with primary congenital glaucoma were included in the study. Racial backgrounds were as follows: 39\% Hispanic, 30\% Caucasian, 10\% African American, and 9\% unknown or unspecified. The mean cup-to-disc ratio and IOP at last visit were 0.52 and $17.2 \mathrm{mmHg}$, respectively. Patients were taking a mean number of 1.12 glaucoma medications, with $51 \%$ of eyes requiring treatment with medication.

As presented in Table 5, visual acuity at the most recent visit was as follows: $41 \%$ of eyes had good visual acuity (20/40 or better), $38 \%$ had moderate visual acuity (20/60 to $20 / 200$ ), and $22 \%$ had poor visual acuity (count fingers to no light perception). It should be noted that this group had the highest proportion of eyes for which Snellen visual acuity could not be measured (54\%).

A majority of eyes ( 75 of 81 ) with primary congenital glaucoma received glaucoma surgery, with seven eyes needing more than one surgery. There were a total of 63 trabeculotomies, seven tube shunts, four cyclodestructive 
Table 2 Race and type of glaucoma in the study patients

\begin{tabular}{|c|c|c|c|c|c|}
\hline & Hispanic, n (\%) & Caucasian, n (\%) & African American, n (\%) & Asian, n (\%) & Other, n (\%) \\
\hline Total & $90(37.7)$ & 7I (29.7) & $49(20.5)$ & $7(2.9)$ & $22(9.2)$ \\
\hline Primary congenital glaucoma & $18(39.1)$ & $14(30.4)$ & $10(21.7)$ & $0(0)$ & $4(8.7)$ \\
\hline Primary juvenile glaucoma & $I(10.0)$ & $5(50.0)$ & $2(20.0)$ & I $(10.0)$ & $I(10.0)$ \\
\hline Secondary glaucoma & $43(39.8)$ & $36(33.3)$ & $19(17.6)$ & I $(0.9)$ & $9(8.3)$ \\
\hline Glaucoma suspects & $28(37.3)$ & $16(2 \mid .3)$ & $18(24.0)$ & $5(6.7)$ & $8(10.7)$ \\
\hline
\end{tabular}

procedures, five trabeculectomies, and four other procedures performed on this group.

\section{Primary juvenile glaucoma}

A total of ten patients and 19 eyes with primary juvenile glaucoma were included in the study. Racial backgrounds were as follows: 50\% Caucasian, 20\% African American, 10\% Hispanic, 10\% Asian, and 10\% undetermined. Mean cup-to-disc ratio was 0.7 , and mean IOP was $16.4 \mathrm{mmHg}$. Thirty-seven percent of patients required surgery and $90 \%$ of eyes required medication, with an average of 2.5 medications. Best-corrected visual acuity was 20/40 or better in 13 eyes (77\%). Tube shunts were the most common surgery performed on this group, although most patients did require any surgery.

\section{Secondary glaucoma}

Almost half of all eyes in the study (45\%) were diagnosed with secondary glaucoma. A total of 108 patients and 140 eyes with secondary glaucoma were included. Forty percent of eyes were from Hispanic patients, 33\% Caucasian, 18\% African American, 1\% Asian, and 8\% undetermined. The mean cup-to-disc ratio for all eyes was 0.55 , and the mean IOP was $18.6 \mathrm{mmHg}$. Patients were on an average of 1.7 glaucoma medications, and $78 \%$ of eyes required medication.
Best-corrected visual acuity was as follows: 55 eyes had good visual acuity (51\%); 21 had moderate visual acuity $(19 \%) ; 33$ had poor visual acuity (30\%); and 32 could not be determined. Fifty-four percent of eyes required surgery. A total of 23 trabeculotomies, 45 tube shunts, 15 cyclodestructive procedures, four trabeculectomies, and eleven other procedures were performed on this group, including anterior chamber washout, surgical iridectomy, vitrectomy, and enucleation.

The most frequent causes of secondary glaucoma included trauma and postsurgical aphakia (see Figure 1). Less common postsurgical causes included pseudophakia, silicone oil placement, and penetrating keratoplasty. This was followed by Sturge-Weber syndrome and anterior segment dysgenesis. In the anterior segment dysgenesis group, Peters anomaly accounted for the majority of eyes (62.5\%), followed by Axenfeld-Rieger syndrome (25\%) and aniridia (12.5\%). We found other, less-common causes of secondary glaucoma, including inflammation, medicationinduced, retinopathy of prematurity, craniosynostosis, and pupillary block.

\section{Glaucoma suspects}

There were 75 patients and a total of 136 eyes included in the study as glaucoma suspects. The patients were composed of $37 \%$ Hispanic, 24\% African American, 21\% Caucasian,

Table 3 Clinical characteristics and type of glaucoma in the study patients

\begin{tabular}{|c|c|c|c|c|c|c|c|}
\hline \multirow[t]{2}{*}{ Type of glaucoma } & \multirow{2}{*}{$\begin{array}{l}\text { Total number } \\
\text { of patients }\end{array}$} & \multirow{2}{*}{$\begin{array}{l}\text { Average IOP } \\
\text { (SD) }\end{array}$} & \multirow{2}{*}{$\begin{array}{l}\text { Cup-to-disc } \\
\text { ratio (SD) }\end{array}$} & \multicolumn{4}{|c|}{ Treatment modality by eyes, $\mathbf{n}(\%)$} \\
\hline & & & & $\begin{array}{l}\text { Surgery } \\
\text { only }\end{array}$ & $\begin{array}{l}\text { Surgery and } \\
\text { medication }\end{array}$ & $\begin{array}{l}\text { Medication } \\
\text { only }\end{array}$ & $\begin{array}{l}\text { No } \\
\text { treatment }\end{array}$ \\
\hline Primary congenital & 46 & $17.2(8.75)$ & $0.52(0.24)$ & $40(49.4)$ & $35(43.2)$ & $6(7.4)$ & $0(0.0)$ \\
\hline Primary juvenile & 10 & $16.4(6.10)$ & $0.71(0.16)$ & $2(10.5)$ & $5(26.3)$ & $12(63.2)$ & $0(0.0)$ \\
\hline Secondary & 108 & $18.6(6.30)$ & $0.55(0.22)$ & $17(12.1)$ & $58(4 \mid .4)$ & $5 I(36.4)$ & $14(10.0)$ \\
\hline Trauma & 32 & I7.3 (6.5I) & $0.40(0.24)$ & $5(15.6)$ & $5(15.6)$ & $13(40.6)$ & $9(28.1)$ \\
\hline Postsurgical & 30 & $17.5(4.33)$ & $0.56(0.21)$ & $4(13.3)$ & $16(53.3)$ & $10(33.3)$ & $0(0.0)$ \\
\hline SWS & 18 & $20.8(7.12)$ & $0.62(0.18)$ & $0(0.0)$ & $14(66.7)$ & $5(23.8)$ & $2(9.5)$ \\
\hline ASD & 16 & $19.9(7.13)$ & $0.55(0.18)$ & $4(14.8)$ & II (40.7) & $10(37.0)$ & $2(7.4)$ \\
\hline Other & 12 & $19.3(7.62)$ & $0.58(0.25)$ & $3(21.4)$ & $5(35.7)$ & $5(37.5)$ & I (7.I) \\
\hline Glaucoma suspects & 75 & I $6.8(4.42)$ & $0.60(0.19)$ & $0(0.0)$ & $0(0.0)$ & II (8.I) & 125 (91.9) \\
\hline
\end{tabular}

Abbreviations: ASD, anterior segment dysgenesis; IOP, intraocular pressure; SD, standard deviation; SWS, Sturge-Weber syndrome. 
Table 4 Ocular surgeries performed and type of glaucoma in the study patients

\begin{tabular}{|c|c|c|c|c|c|c|}
\hline & $\begin{array}{l}\text { Trabeculotomy, } \\
\text { n (\%) }\end{array}$ & $\begin{array}{l}\text { Tube shunt, } \\
\text { n (\%) }\end{array}$ & $\begin{array}{l}\text { Cyclodestruction, } \\
\text { n (\%) }\end{array}$ & $\begin{array}{l}\text { Trabeculectomy, } \\
\text { n (\%) }\end{array}$ & $\begin{array}{l}\text { Other, }{ }^{a} \\
\text { n (\%) }\end{array}$ & $\begin{array}{l}\text { No surgery, } \\
\text { n (\%) }\end{array}$ \\
\hline Total eyes, n (\%) & $86(25.1)$ & $57(16.6)$ & $19(5.5)$ & II (3.2) & $15(4.4)$ & $155(45.2)$ \\
\hline Primary congenital glaucoma & $63(70.8)$ & $7(7.9)$ & $4(4.5)$ & $5(5.6)$ & $4(4.5)$ & $6(6.7)$ \\
\hline Primary juvenile glaucoma & $0(0.0)$ & $5(26.3)$ & $0(0.0)$ & $2(10.5)$ & $0(0.0)$ & $12(63.2)$ \\
\hline Secondary glaucoma & $23(14.1)$ & $45(27.6)$ & $15(9.2)$ & $4(2.5)$ & II (6.7) & $65(39.9)$ \\
\hline Trauma & $0(0.0)$ & $8(22.2)$ & $3(8.3)$ & I (2.8) & $3(8.3)$ & $21(58.3)$ \\
\hline Postsurgical & $9(16.1)$ & $18(32.1)$ & $6(10.7)$ & $0(0.0)$ & $5(8.9)$ & $18(32.1)$ \\
\hline sWS & $10(40.0)$ & $5(20.0)$ & I $(4.0)$ & $2(8.0)$ & $0(0.0)$ & $7(28.0)$ \\
\hline ASD & $4(12.9)$ & $7(22.6)$ & $5(16.1)$ & $0(0.0)$ & $3(9.7)$ & $12(38.7)$ \\
\hline Other & $0(0.0)$ & $7(58.3)$ & $0(0.0)$ & I (8.3) & $0(0.0)$ & $4(33.3)$ \\
\hline Glaucoma suspect & $0(0.0)$ & $0(0.0)$ & $0(0.0)$ & $0(0.0)$ & $0(0.0)$ & $75(100.0)$ \\
\hline
\end{tabular}

Note: alncluded goniotomy, enucleation, vitrectomy, anterior chamber washout, and surgical peripheral iridectomy.

Abbreviations: ASD, anterior segment dysgenesis; SWS, Sturge-Weber syndrome.

5\% Asian, and 11\% undetermined. The mean cup-todisc ratio for all eyes was 0.60 , and the mean IOP was $16.8 \mathrm{mmHg}$. The mean number of glaucoma medications for the group was 0.2 , and $8 \%$ of eyes were using medication at the most recent visit.

Best-corrected visual acuity was $20 / 40$ or better in 108 eyes (96\%), with only 23 eyes undeterminable. No glaucoma surgeries were performed on any eye in the glaucoma suspect group. Suspicious discs were the most common cause for glaucoma suspicion and were seen in $76 \%$ of patients (see Table 6). Thirty-two percent of patients were found to have high IOP, and a family history of glaucoma was found in $17 \%$. Other reasons for glaucoma suspicion included Sturge-Weber syndrome, ocular melanosis, Axenfeld-Rieger syndrome, and retinopathy of prematurity.

\section{Discussion}

Childhood glaucoma is a vision-threatening disease, with a broad range of causes, which can present at any age. Preventing vision loss in pediatric patients can make possible a lifetime of independence and productivity. This makes early identification and treatment of glaucoma in children vitally important. This study identifies patterns of disease in childhood glaucoma and glaucoma suspects at a tertiary referral center in a large, multiethnic, urban population in the United States.

In this study, $23 \%$ of patients had primary glaucoma, $45 \%$ had secondary glaucoma, and $31 \%$ were glaucoma suspects, representing a well-balanced cross-section of pediatric patients that ophthalmologists are likely to encounter with glaucoma or suspected glaucoma. Of the primary childhood glaucomas, congenital glaucoma was the most common, consistent with findings of previous studies. ${ }^{4-6}$ This study does have a small sample size of ten patients for primary juvenile glaucoma. In contrast to our previously published preliminary results with the DGR, we found in this study that males were more likely to be diagnosed with childhood glaucoma, which is consistent with other studies. ${ }^{5,11,15,16}$ This study provides a much larger sample size of patients with childhood glaucoma compared to our preliminary results from the DGR. Secondary glaucoma associated with trauma was noted to have the largest proportion of male patients, as seen in other studies. ${ }^{5,7}$

In this study, Hispanics were the most common racial group found to have childhood glaucoma, followed by Caucasians and then African Americans. It is possible that this reflects the demographics of the patient population in North Texas. The patients in this study were drawn from a children's hospital that serves a large tertiary referral

Table 5 Best-corrected visual acuity and type of glaucoma in the study patients

\begin{tabular}{|c|c|c|c|c|}
\hline \multirow[t]{2}{*}{ Type of glaucoma } & $20 / 40$ or better & $20 / 60-20 / 200$ & CF-NLP & Undetermined \\
\hline & Eyes, n (\%) ${ }^{a}$ & Eyes, n (\%) ${ }^{a}$ & Eyes, $n(\%)^{a}$ & Eyes, n (\%) \\
\hline No glaucoma diagnosis & $58(89.2)$ & $4(6.2)$ & $3(4.6)$ & $17(20.7)$ \\
\hline Primary congenital & I5 (40.5) & I 4 (37.8) & $8(2 \mid .6)$ & $44(54.3)$ \\
\hline Primary juvenile & $13(76.5)$ & $2(11.8)$ & $2(11.8)$ & I (5.6) \\
\hline Secondary & $55(50.5)$ & $21(19.3)$ & $33(30.3)$ & $32(22.7)$ \\
\hline Glaucoma suspects & $108(96.4)$ & $4(3.6)$ & $0(0.0)$ & $23(17.0)$ \\
\hline
\end{tabular}

Note: aPercentage of eyes for which visual acuity could be measured.

Abbreviations: CF, count fingers; NLP, no light perception. 


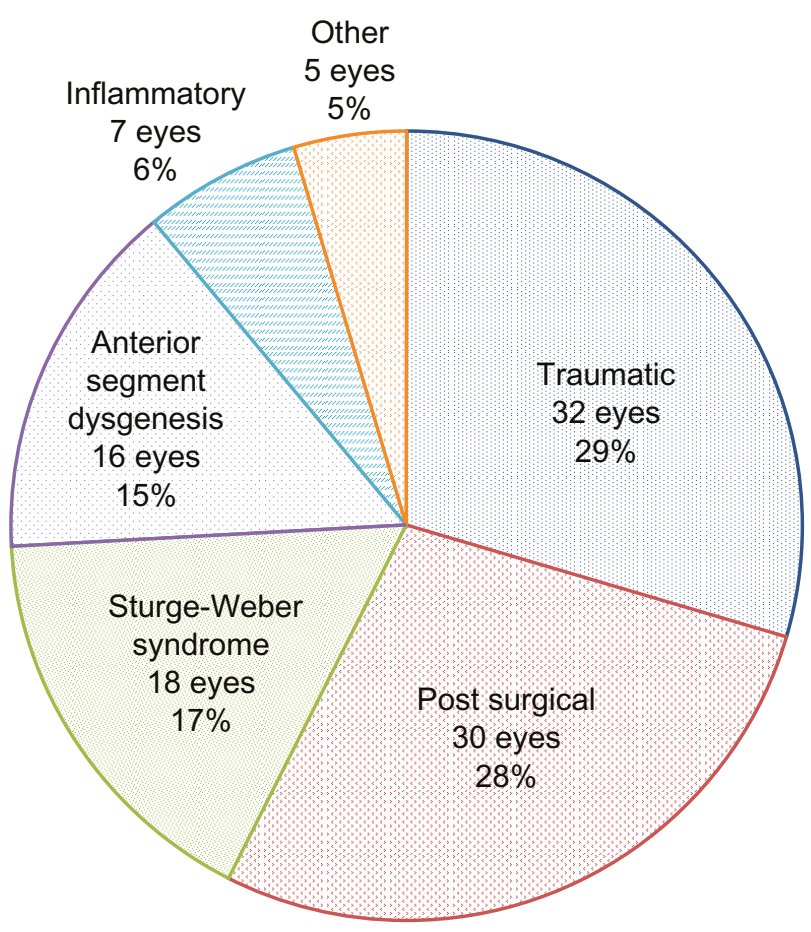

Figure I Etiologies of secondary glaucoma.

academic medical center. Approximately $85 \%$ of these patients are insured by Medicaid, the US health program for families and individuals with low income and resources. The results from this study suggest that Hispanics may indeed have a similar risk of developing childhood glaucoma as other racial populations. Other studies have found an increased prevalence of open-angle glaucoma and ocular hypertension in the Latino population, although they have focused primarily on adults over 40 years of age. ${ }^{18,19}$ The prevalence of open-angle glaucoma in the adult Hispanic population has been estimated to be between that of Caucasians and African Americans. ${ }^{19}$ Further studies should be done to better evaluate the characteristics of childhood glaucoma in the Hispanic population.

Given that many patients in this study were too young to use the Snellen eye chart at the time of the last exam, we

Table 6 Reasons for glaucoma suspicion in the study patients

\begin{tabular}{ll}
\hline & Patients $(\mathbf{n}=\mathbf{7 5}), \mathbf{n}(\%)$ \\
\hline Suspicious discs & $57(76.0)$ \\
Elevated intraocular pressure & $24(32.0)$ \\
Strong family history & $13(17.3)$ \\
Sturge-Weber syndrome & $9(12.0)$ \\
Ocular melanosis & $2(2.7)$ \\
Axenfeld-Rieger syndrome & $2(2.7)$ \\
Retinopathy of prematurity & $\mathrm{I}(1.3)$ \\
Ocular trauma & $\mathrm{I}(1.3)$ \\
\hline
\end{tabular}

were unable to determine a final visual acuity in all patients. From those patients who were able to use a Snellen eye chart, not surprisingly, the glaucoma suspects had the best visual acuity, with $96 \%$ of eyes seeing better than $20 / 40$. Interestingly, only $41 \%$ of eyes with primary congenital glaucoma had good visual acuity, compared to $77 \%$ of eyes with primary juvenile glaucoma. The better vision seen with primary juvenile glaucoma leads us to speculate that a glaucoma diagnosis may be delayed with these patients given their normal visual acuity earlier in life and lack of physical signs that would otherwise have been detected at a younger age. We also noted that secondary glaucoma patients had the largest proportion of eyes with poor visual acuity, at $30 \%$. This is consistent with previous studies that have found a trend towards better visual outcomes in primary, rather than in secondary, glaucoma. ${ }^{15,20}$

We found differences in treatment modalities among the types of glaucoma. While surgery was used predominantly for primary congenital glaucoma, medication was used more frequently for juvenile glaucoma. While IOP was less than $21 \mathrm{mmHg}$, on average, for all groups, the cup-to-disc ratio and number of medications was highest for the juvenile group. Given that juvenile glaucoma may not be diagnosed until late into the disease process, visual loss may occur before detection or treatment. The increased use of medications in the juvenile glaucoma group may indicate better compliance with older age or better tolerability of the side effects of medical treatment. As more patients are added to the DGR, we anticipate these observations to become more apparent.

Trabeculotomy was the most commonly performed surgery, followed by glaucoma tube-shunting procedures. Over $65 \%$ of eyes in the study underwent at least one glaucoma surgery, excluding glaucoma suspects. Primary congenital glaucoma eyes were more likely to receive trabeculotomy surgery, while secondary and primary juvenile glaucoma eyes were more likely to receive tubeshunt surgery.

Medication plays an important role in the treatment of childhood glaucoma. A majority of patients in this study (70\%) were on at least one glaucoma medication at their most recent clinical visit. Of those patients requiring medication, many required more than one. A large proportion of patients still required medications even after surgery. This highlights the importance of the proper use of medications with knowledge of their unique side effects in the pediatric population. Topical carbonic anhydrase inhibitors, prostaglandin analogs, and beta-blockers were the 
most commonly used medications, while alpha-agonists and systemic carbonic anhydrase inhibitors were used the least.

Secondary glaucoma in pediatric patients differs significantly from that in adult patients, as those with unique developmental anomalies and childhood diseases make up a much larger percentage of pediatric glaucoma patients than in the adult population. However, trauma is also a major cause of secondary glaucoma in both children and adults and has often not been found or has been excluded as a major cause of secondary childhood glaucoma in previous studies. ${ }^{4,6,20}$ More recent studies, however, are showing trauma as a major cause of childhood glaucoma. Qiao et al's Beijing study did find that traumatic and aphakic glaucoma were the most common types of childhood glaucoma following congenital glaucoma in a large Chinese population. ${ }^{5}$ Aponte et al's Olmstead County study found that traumatic and surgical causes of childhood glaucoma were the most common; however, this population was predominantly white. ${ }^{7}$ Our study in a large, multiethnic, urban population confirms the role trauma plays in childhood glaucoma. This suggests the importance of closely following children after ocular trauma and screening for glaucoma. This study also found a similar proportion of causes of nontraumatic secondary glaucoma as in previous studies, with postsurgical causes, generally aphakia, being the most common. ${ }^{4,20}$

The DGR enables a broad, cross-sectional view of patients seen by ophthalmologists for a multitude of glaucoma types across all ages in a large, multiethnic, urban population. Using this registry, we studied the epidemiology and characteristics of childhood glaucoma, including patients with traumatic glaucoma and glaucoma suspects. As with most epidemiological and retrospective studies, this study is limited to the demographics in a single geographical region at a single point in time. Although likely representative of the population studied, we found that a high proportion of childhood glaucoma patients were of Hispanic background, which has not been previously discussed in the literature and warrants further investigation. As more pediatric patients are added to the DGR, we hope to explore this further and compare the clinical characteristics between various ethnic groups.

\section{Conclusion}

Trauma-related glaucoma is a common cause of childhood glaucoma, and we recommend that children with a history of ocular trauma be monitored closely. As more pediatric patients are added to the DGR, it will become an even more powerful tool with which to analyze childhood glaucoma in an effort to prevent visual disability in children around the world.

\section{Acknowledgments}

This study was supported in part by an unrestricted grant from Research to Prevent Blindness, Inc, New York, NY, USA.

\section{Disclosure}

The authors report no conflicts of interest in this work.

\section{References}

1. Durnian JM, Cheeseman R, Kumar A, Raja V, Newman W, Chandna A. Childhood sight impairment: a 10-year picture. Eye (Lond). 2010;24(1):112-117.

2. Bhattacharjee H, Das K, Borah RR, et al. Causes of childhood blindness in the northeastern states of India. Indian J Ophthalmol. 2008;56(6):495-499.

3. Dorairaj SK, Bandrakalli P, Shetty C, RV, Misquith D, Ritch R. Childhood blindness in a rural population of southern India : prevalence and etiology. Ophthalmic Epidemiol. 2008;15(3):176-182.

4. Papadopoulos M, Cable N, Rahi J, Khaw PT; BIG Eye Study Investigators. The British Infantile and Childhood Glaucoma (BIG) Eye Study. Invest Ophthalmol Vis Sci. 2007;48(9):4100-4106.

5. Qiao CY, Wang LH, Tang X, Wang T, Yang DY, Wang NL. Epidemiology of hospitalized pediatric glaucoma patients in Beijing Tongren Hospital. Chin Med J. 2009;122(10):1162-1166.

6. Taylor RH, Ainsworth JR, Evans AR, Levin AV. The epidemiology of pediatric glaucoma: the Toronto experience. J AAPOS. 1999; 3(5):308-315.

7. Aponte EP, Diehl N, Mohney BG. Incidence and clinical characteristics of childhood glaucoma: a population-based study. Arch Ophthalmol. 2010;128(4):478-482.

8. Levy J, Carmi R, Rosen S, Lifshitz T. Primary congenital glaucoma presenting within the first three months of life in a Bedouin population. J Glaucoma. 2005;14:139-144.

9. Bejjani BA, Stockton DW, Lewis RA, et al. Multiple CYP1B1 mutations and incomplete penetrance in an inbred population segregating primary congenital glaucoma suggest frequent de novo events and a dominant modifier locus. Hum Mol Genet. 2000;9:367-374.

10. Gencík A. Epidemiology and genetics of primary congenital glaucoma in Slovakia. Description of a form of primary congenital glaucoma in gypsies with autosomal-recessive inheritance and complete penetrance. Dev Ophthalmol. 1989;16:76-115.

11. deLuise VP, Anderson DR. Primary infantile glaucoma (congenital glaucoma). Surv Ophthalmol. 1983;28(1):1-19.

12. Sarfarazi M, Stoilov I, Schenkman JB. Genetics and biochemistry of primary congenital glaucoma. Ophthalmol Clin North Am. 2003; 16(4):543-554.

13. Turalba AV, Chen TC. Clinical and genetic characteristics of primary juvenile-onset open-angle glaucoma (JOAG). Semin Ophthalmol. 2008;23(1):19-25.

14. Song J, Stinnett SS, Whitson JT, Kooner KS. Ten-year surgical experience with childhood glaucoma. J Pediatr Ophthalmol Strabismus. 2003;40(1):11-18.

15. Barsoum-Homsy M, Chevrette L. Incidence and prognosis of childhood glaucoma. A study of 63 cases. Ophthalmology. 1986;93(10): 1323-1327.

16. Kooner KS, Joseph A, Shar A, et al. Dallas Glaucoma Registry: preliminary results. J Clin \& Exp Ophthalmol. 2011;2(6):1-5. 
17. State and County QuickFacts: Dallas County, Texas [webpage on the Internet]. Washington DC: United States Census Bureau; 2013 [updated June 6, 2013; cited February 18, 2013]. Available from: http://quickfacts. census.gov/qfd/states/48/48113.html. Accessed June 18, 2013.

18. Quigley HA, West SA, Rodriguez J, Munoz B, Klein R, Snyder R. The prevalence of glaucoma in a population-based study of Hispanic subjects. Arch Ophthalmol. 2001;119:1819-1826.
19. Varma R, Ying-Lai M, Francis BA, et al; Los Angeles Latino Eye Study Group. Prevalence of open-angle glaucoma and ocular hypertension in Latinos: The Los Angeles Latino Eye Study. Ophthalmology. 2004;111:1439-1448.

20. Biglan AW. Glaucoma in children: are we making progress? JAAPOS. 2006;10:7-21.

\section{Publish your work in this journal}

Clinical Ophthalmology is an international, peer-reviewed journal covering all subspecialties within ophthalmology. Key topics include: Optometry; Visual science; Pharmacology and drug therapy in eye diseases; Basic Sciences; Primary and Secondary eye care; Patient Safety and Quality of Care Improvements. This journal is indexed on

\section{Dovepress}

PubMed Central and CAS, and is the official journal of The Society of Clinical Ophthalmology (SCO). The manuscript management system is completely online and includes a very quick and fair peer-review system, which is all easy to use. Visit http://www.dovepress.com/ testimonials.php to read real quotes from published authors. 